\title{
Higher Education in Taiwan: An Analysis of Trends Using the Theory of Punctuated Equilibrium
}

\author{
Yu-Lan Huang \\ Yuan Ze University, Taoyuan, Taiwan; Tamkang University, New Taipei, Taiwan \\ Dian-Fu Chang \\ Tamkang Univeristy, New Taipei, Taiwan \\ Chiung-Wen Liu \\ Tamkang Univeristy, New Taipei, Taiwan; Hua Shiun Elementary School, Taoyuan, Taiwan
}

\begin{abstract}
Taiwan is currently facing the serious challenge of decreasing enrollment in higher education institutes (HEIs) due to the oversupply of these institutions and decreasing birthrates. This has necessitated that policymakers implement new policies to meet the demands of the market. This paper uses punctuated equilibrium theory (PET) to explain the circumstances that led to the overexpansion of Taiwan's higher education institutions over the past decades. This article also analyzes the social contexts and ramifications of social conflict regarding public expectations and policy changes in the ideology of the educational reform movement.
\end{abstract}

Keywords: higher educational institutes (HEIs), oversupply educational system, the market mechanism, punctuated equilibrium theory (PET)

\section{Introduction}

This paper considers the history of higher education in Taiwan before martial law was introduced. However, it pays more attention to the implications of the education reform movement of the 1990s. After the lifting of martial law in 1987, the Taiwan government faced a torrent of demands for the reform of education (Pan, 2011). One of the consequences of the demands was giving autonomy to HEIs. Despite the prediction that in the next few years, enrollment at HEIs would decline due to lower national birthrates (Hsueh, 2003), there was a rapid growth in tertiary education institutions in Taiwan over a short period of time. Ten years later in 2003, the researchers who could foresee the looming problems formed a group and wrote letters of ten thousand words in an attempt to halt the chaos of the educational reform (Hsueh, 2003, Hwang, 2003). However, their argument seemed to be ineffective in stopping the expansion of tertiary institutions. Between 1996 and 2003, the number of universities grew from 24 to 67, an increase of 279\%. By 2015, 126 universities had been established or upgraded from colleges (MOE, 2016b). Ultimately, the policy changes and autonomy in

\footnotetext{
Yu-Lan Huang, Doctor Candidate, Doctoral Program of Educational Leadership and Technology Management, College of Education, Tamkang University, Taoyuan, Taiwan; Lecturer, International Language and Culture Center, Yuan Ze University, Taoyuan, Taiwan.

Dian-Fu Chang, Doctor in Education, Columbia University, Dean, Graduate Institute of Educational Policy and Leadership, Tamkang University.

Chiung-Wen Liu, Doctoral Program of Educational Leadership and Technology Management, College of Education, Tamkang University, New Taipei, Taiwan. Director of Academic Affairs, Hua Shiun Elementary School, Taoyuan, Taiwan.
} 
education development, which was intended to improve the situation, actually caused more problems: the oversupply of institutions offering higher education, declining enrollment at HEIs and by far the highest admission rate of all Asian countries. This paper utilizes punctuated equilibrium theory PET) to analyze and explain the trends in higher education development in Taiwan. The data collected in this study illustrate what equilibrium may be expected in the next years.

\section{Review of the History of Taiwan's Higher Education}

During the 30 years from 1987 to 2017, higher education in Taiwan has changed dramatically. The government has encountered new waves of educational reforms and unexpected overexpansion. The ongoing challenges, such as the oversupply of HEIs, national declining birthrate, and decreasing enrollment at universities and colleges, have compelled the Ministry of Education (MOE) to implement certain strategies as policy intervention and policy changes to balance the market mechanism.

\section{Higher Education in Taiwan before the Lifting of Martial Law}

A review of the past hundred years of education in Taiwan, indicates that there have been three main phases (Pan, 2011). The focus of the first period, 1912-1949, was on developing new educational concepts that combined Eastern and Western educational perspectives. In 1928, under the rule of the Japanese colonial government, the first national university, Taiwan Imperial University, was established. The second period started in 1949, when the Kuomintang government moved to Taiwan from mainland China. During the 38 years of martial law, patriotism became fully integrated at all levels of the education system - from elementary to higher education. The third period began in 1987 when the government officially announced the lifting of martial law on July 15 (Law, 2002; Tsai \& Shavit, 2003). This was a milestone as it was the beginning of democracy and openness in many fields including the media, the electoral system, human rights and education. (Hsung, Chang, Lin, 2010), which weakened the authoritarian dictatorship of the Kuomintang government (Tu, 2007). Because of the movement towards democratization, liberalization, and pluralism (Pan, 2011), demands for the deregulation of educational policies and educational reform swept across the country. The result was the deconstruction of the prevailing policy and the reconstruction of education policy in the following decades (Chin, Kuo, Wu, 2002).

\section{The Expansion of Higher Education after the Lifting of Martial Law}

Since the late 1980s, governments in many nations have gone through the process of political democratization, the expanding of human rights and economic transformation in response to the worldwide trend of neo-liberalism and globalization (Schofer \& Hironaka, 2005). Unsurprisingly, HEIs in many countries have also been restructured and had their systems reorganized (Giroux, 2002). On the one hand, Taiwan followed this worldwide trend during that time but on the other hand, Taiwan had a top-down policy whereby people, who had not had a voice for 38 years, were expected to comply with orders from above (May, Chang, \& Lin, 2010). As soon as martial law was lifted, various social movements emerged as a consequence of the liberation from the long-term political and social suppression and groups actively took part in democratic demonstrations during the short period of time (Hwang, 2016, p. 80). The message conveying the social expectations of the movements reinforced market drivers in the higher education system that considered all aspects of transformation including a sharp increase of HEIs and enrollments (Chou, 2015). This was perhaps reinforced by one of the Chinese sayings: "Scholarly work is superior to everything" and explains why the 
majority of parents in Taiwan expect their children to study in HEIs (Lin, 2014), leading to an increase in competitiveness. Therefore, the public stereotype that an academic background and having a diploma are relatively more important than long-term training has become embedded in the society (Ho, 2012).

As a result of the "410 Demonstration for Educational Reform" on April 10, 1994, a full-scale reform of education was initiated. The movement aimed to modernize the education system, draft a fundamental education law, establish more high schools and universities, and change of the idea of "de-centralization" to "individualization" (Tu, 2007). The deregulation of the education policies followed by the 410 Educational Reform Movement contributed significantly to an expansion of HEIs over the following years, along with an upgrade of a number of two-year and five-year junior colleges, institutes of technology, universities of technology and general universities (Chang, Lin, \& Chen, 2013). The growth in the number of HEIs and undergraduate students indicates that there was rapid expansion of higher education facilities during that period (Chen, 2010). These quantitative increases have resulted in Taiwan's population having massive access to higher education and there has been a general reduction in education inequality (Hon, 2012).

\section{Oversupply of the Higher Education Structures}

Due to the rapid growth in the number of universities in Taiwan, higher education has expanded at an extraordinary pace (Chang, 2012; Chou, 2014). Accordingly, the education system of Taiwan has transitioned from higher education being for the elite (with an acceptance rate of below 15\%) to higher education being available to the masses (with an acceptance rate of above 50\%) (Tang, 2003; Yang 2001; Trow, 2006, Chan \& Lin, 2015). However, the White Paper on Talent Cultivation released by the MOE in 2013, pointed out that Taiwan's birthrate had been declining since the mid-1990s (MOE, 2013b; Kuo, 2016), and it indicated that the policy of higher education expansion had been carried out without due consideration of the demographic changes (see Figure 1). Hsueh (2009) also emphasized that Taiwan launched a new wave of education reforms in the 1990s without detecting the fact that the number of students had been decreasing. The impact of these factors above has resulted in the implications that some colleges now have more vacancies than they used to have. In 2016, 203 departments in 23 universities had 2,933 vacant seats, and six universities attracted less than $50 \%$ of their required enrollment last year (UDN news, 2016). Inevitably, an oversupply of HEIs has led to the crisis of declining enrollment.

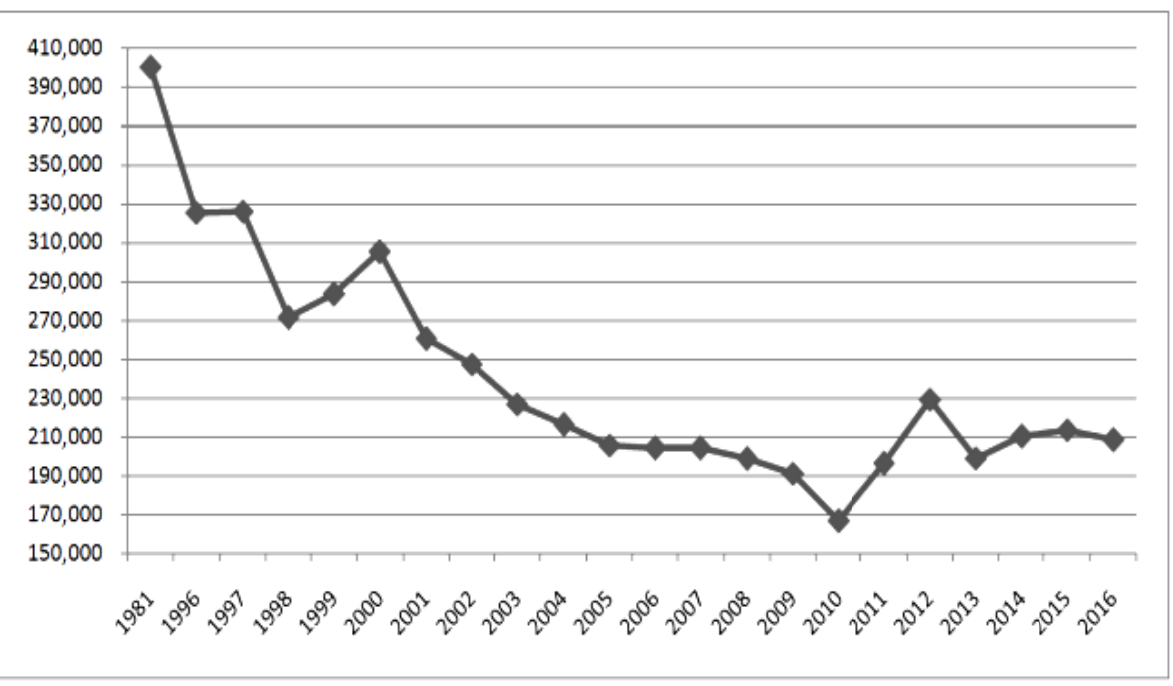

Figure 1. Declining birthrate in Taiwan. 


\section{MOE’s Intervention and New Policies}

Due to the ease of access to higher education and the universal higher education system, in 2016, 97.11\% of those who applied were admitted to tertiary education (News, 2016). Some researchers have contributed academic inflation and the increasing depreciation of the value of diplomas to the overexpansion in higher education (Lin, 2014; Chan \& Lin, 2015; Chou, 2015).

The KMT government has been prompted to respond to the effect of declining birth rate and decreasing enrollment (see Figure 2) in HEIs and in March 2015, The MOE launched the program "Higher Education Innovation and Transformation” (MOE, 2015). This program proposes four strategies: promoting advanced talent, providing guidance and support to universities that are closing, reshaping the HEIs' paradigm, and encouraging HEIs' cooperation for merging. The program focuses on reallocating higher education resources and developing multiple management models. The policy, apparently, aims to build a new environment by integrating industry, teaching and research in HEIs (MOE, 2016c). The MOE also proposed merging between eight and twelve public universities and closing between twenty and forty private universities by 2023 to balance declining enrollment and the declining birthrate in Taiwan.

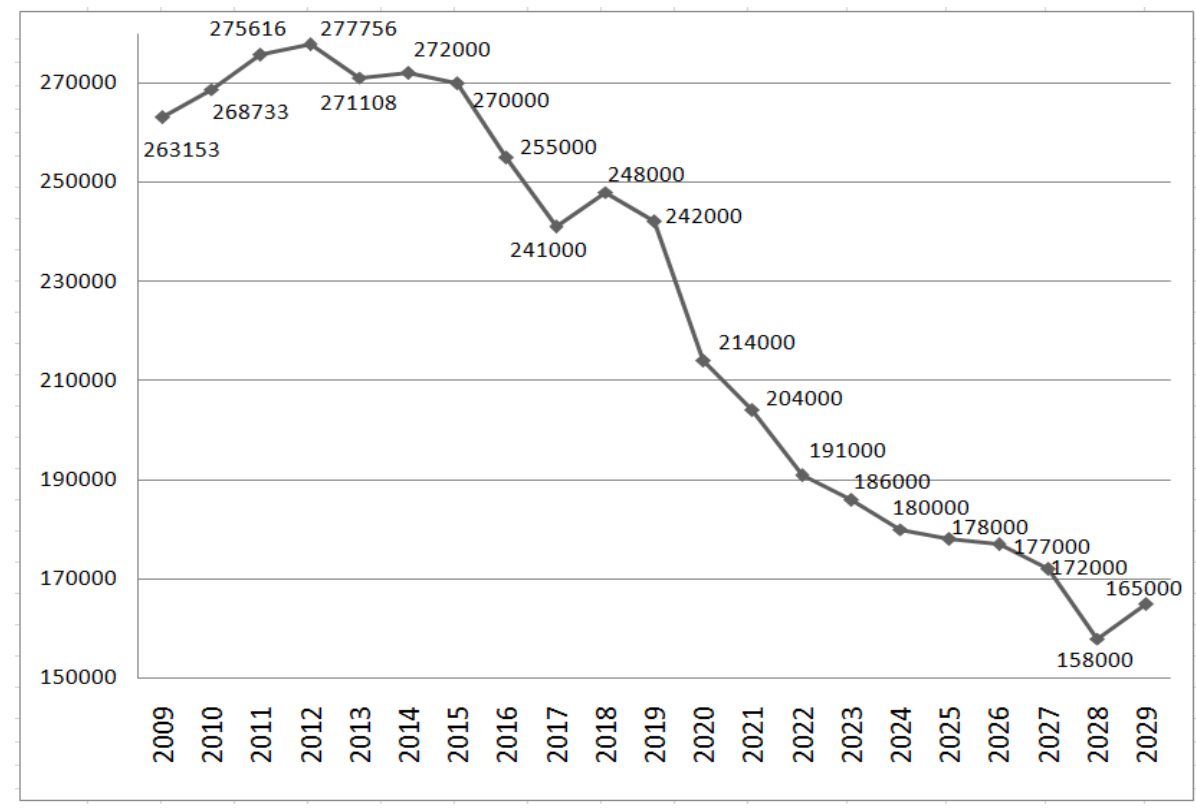

Figure 2. Projecting enrolment.

\section{Conceptual Framework: Punctuated Equilibrium Theory (PET)}

\section{What is the Punctuated Equilibrium Theory?}

The term "punctuated equilibrium" was generated from its use in the natural science to describe the occurrence of dramatic shifts that occur as extraordinary events rather than the gradual and systematic development that normally occurs in evolutionary processes (Gould \& Eldredge, 1977; Baumgartner \& Jones 1991). Political scientists Frank Baumgartner and Bryan Jones, borrowing from Gould and Eldredge’s findings in 1972 of punctuated equilibriam in evolutionary biology, contended that the degree of change in public policy often happens relatively slowly and incrementally (Baumgartner \& Jones, 2009). However, occasionally, they argued, public policy change can also occur sharply over a short period of time due to an outside exogenous 
shock (such as a trigger event) which is followed again by a new pattern of gradual and incremental policy change (Baumgartner, 2006; Baumgartner \& Jones, 2009).

In public policy, the punctuated equilibrium model (Baumgartner \& Jones, 1993) proposes that once an idea gains attention, it would expand rapidly and possibly become unstoppable (see Figure 3). Many ideas claim attention, but at some point, a specific incident or a change in the environment will lead to policy change. The process usually comes from external events that disrupt the political system; expressly, the circumstances that punctuate its equilibrium (Cerna, 2013). More precisely, punctuated equilibrium is the process of interaction between beliefs and values in respect of a particular policy (termed policy images - blends of information and emotion) within existing institutions such as government departments, congressional committees and the courts, where authoritative decisions are made (termed venues of policy action).

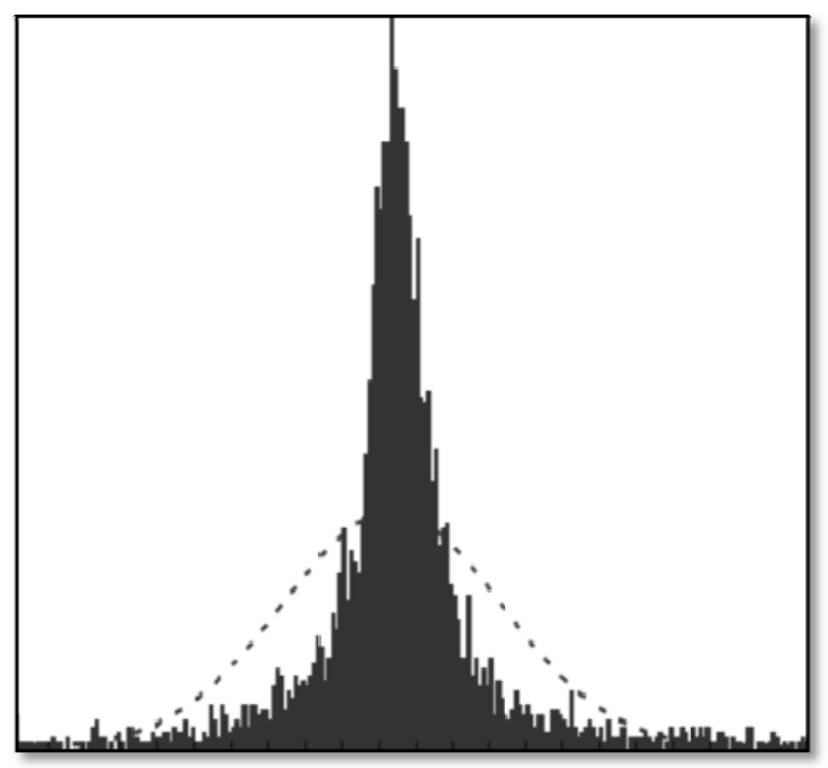

Figure 3. The rapid change of PET.

While there may be intense periods of attention to some issues, this may prompt new ways to frame and solve old policy problems. Further explanation comes from the power of participants either to minimize attention and maintain an established frame of reference, or to expand attention to new audiences in the hope of generating the type of conflict and debate necessary to effect major policy change (True, Jones, \& Baumgartner, 2007, p. 157). PET is utilized to explain the relationship between social conflict, policy debate, and stakeholders in formal institutions after long-term stability. PET is also explicitly adopted to study policy dynamics which usually lead to policy change and further stability after the change.

\section{PET in Policymaking and Changes}

PET seeks to explain political processes which are generally characterized by stability, change, or even large-scale reforms. While both stability and change are important components of the policymaking process, most policy models have been designed to explain either the stability or the change. PET encompasses both (True et al, 2007). PET also suggests that policy change follows a mutually-reinforcing process of increased attention, venue shift and shifting policy images (True et al, 2007, p. 160). As True and colleagues point out, PET emphasizes two parts of the process leading up to government policy decisions-issue definition and 
agenda setting. For instance, when issues are defined while the public interprets them in different ways, existing policies can either be reinforced or questioned. If a policy is constantly questioned, the possibility is created for dramatic change in the policy. When a single aspect of a policy issue is widely supported, this usually suggests a political monopoly (True et al, 1999). A policy monopoly has been defined as an institutional structure that is responsible for policymaking in an issue area, and its responsibility is supported by some powerful idea or image. This image is generally connected to core political values and can be communicated simply and directly to the public (Baumgartner \& Jones, 1993, pp. 5-7). However, if there is more disagreement or conflict about how to solve the policy problem, competing groups may select different policy images. This explains both periods of extreme stability and short periods of rapid political change (Baumgartner \& Jones, 1991).

Punctuated equilibrium is explicitly a theory of policy dynamics as it focuses on the mechanisms that lead to policy change (Jones \& Baumgartner, 2012). Changes in policy activity can occur in policymaking as public understandings of existing problems (True et al, 1999). In essence, PET is the concept of how political conflicts, when represented by debates in public, can lead to change.

\section{Data Analysis and Discussion}

The trends shown in Taiwan's higher education policy, taking into account the rapid growth of the number of institutions in the past decades and the probable future decline of enrollment in the coming years, may be explained by PET for its policymaking process.

\section{Data Collection: Higher Education Expansion and Declining Birthrates}

The data collected from latest information released by the MOE in March of 2016, analyzing the trends in higher education in Taiwan, include the growth of HEIs from 1987 to 2016. The data includes the number of five-year junior colleges, two-year colleges, and four-year institutions of technology and universities. Figure 4 reveals the growth in the total numbers of colleges and universities. It can be seen that the number of junior colleges and colleges decreased while the number of universities increased (this was because many of the colleges had been upgraded to universities), with 163 higher educational institutes (HEIs) in 2012.

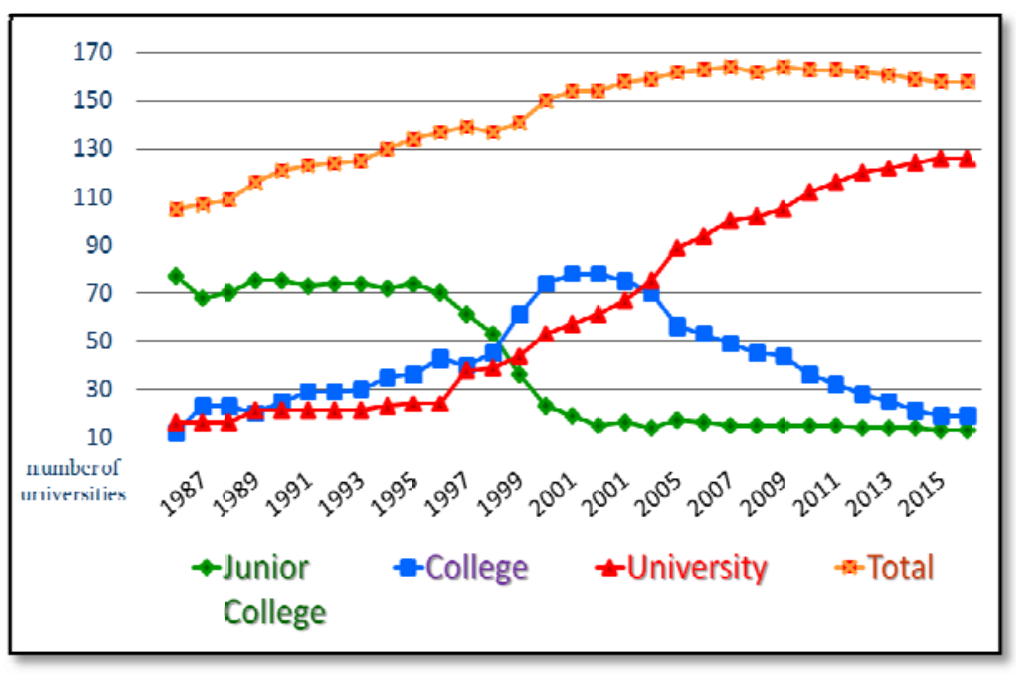

Figure 4. The growth of HEIs. 
Figure 5 shows the rapid expansion of universities in the past years. While there were only 24 universities in 1996, in 1997 the number had grown to 38-a 50\% increase in only one year. The expansion continued and by 2006 there were 79 universities, an increase of 400\%. In 2015, Taiwan had 126 universities reflecting a growth of 525\% from the 16 universities in 1986 .

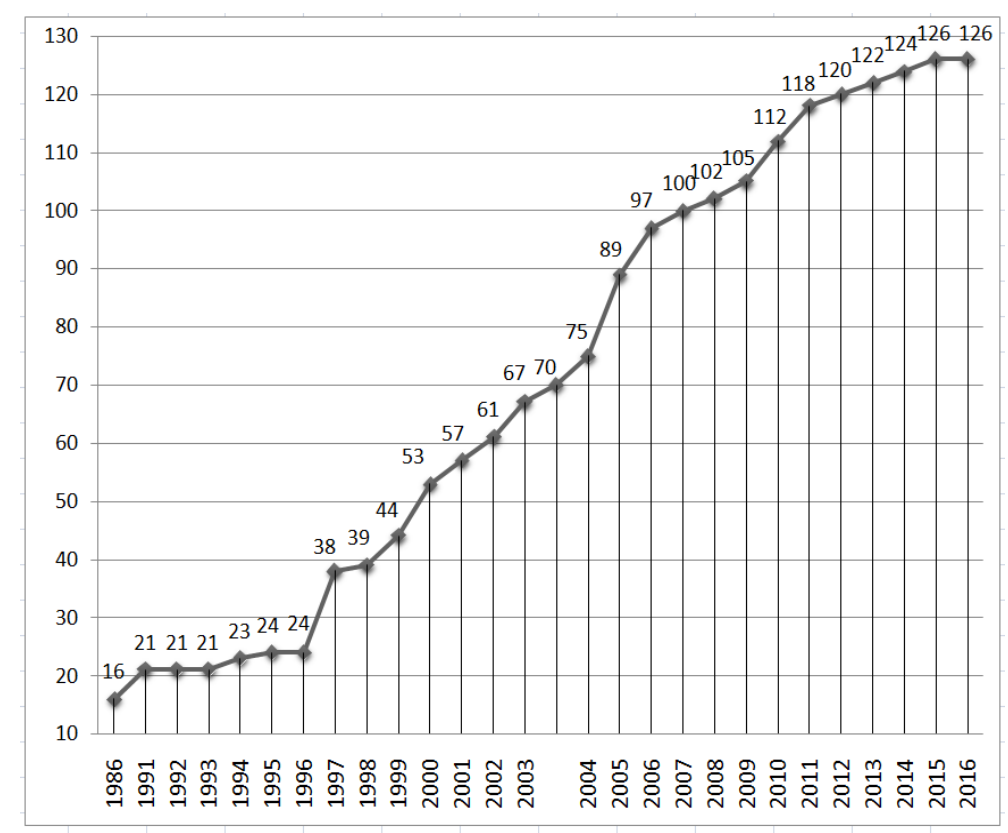

Figure 5. Higher education expansion in Taiwan.

With regard to admission to universities, high school graduates have two options when applying for acceptance by universities in Taiwan. One is to apply using the results of the University Entrance Examination in Subject Competence (SAT I). The applicants usually are required to be interviewed to confirm their qualification. The students who are not accepted or want to enroll in a better university will take the University Entrance Examination in Specified Subjects (SAT II).

In this paper, the rate of admission from the results of the SAT II applications is considered as it adequately represents the admission rate. This is because the actual rates of admission must have been higher than the percentage demonstrated in Figure 3 as $60-70 \%$ of graduates had already been accepted after the SAT I had been written.

The university admission rate has increased from about 20\% of applications before 1970 to 49 percent in 1996 and higher than 90\% in 2006, This is amongst the highest of any Asian country (MOE, 2013b). In 2016, the university acceptance of students with the SAT II reached 97.11\%. During the period from 1984 to 2012, the number of students in higher education grew from 412,381 to 1,339,848, representing a 325\% increase (MOE, 2015). Figure 3 shows that the admission rate between 1973 and 2016 was the most rapid in the past twenty years.

This researcher also collected the records of the national birthrate from 1981 to 2016. Figure 1 indicates that since 1981, birthrates in Taiwan have been steadily declining. Based on this, Figure 2 shows the projected decline in freshmen student numbers from 2015 to 2023. Analysis of the above data above reveals the fact that Taiwan's higher education system is now oversupplied and needs to be changed to factor in the projected declining birthrate. 


\section{Analyzing the Policies Using PET}

Baumgartner \& Jones (2009) noted the theoretical characteristics of punctuated equilibrium in public policy. They theory is that public policy can sometimes change rapidly over a short period of time due to an external shock. In Taiwan's history, the 410 Education Reform Movement in 1994 could be considered a "trigger event" or basis for change, according to the punctuated equilibrium model (Baumgartner, 2006), after the long-term stability during the period of martial law. The campaign disturbed and disrupted the equilibrium of monopolies who were the policymakers in the MOE (venue) and government officials whose power would influence policymaking at that time. Encountering these urgent demands for educational change, and realizing the need to address the issues, the MOE (venue of policy action) held its seventh National Education Conference in June 1994 (MOE, 1994b). The MOE reported that it had agreed on two issues (policy images): to reduce the pressure on students who wanted to pursue higher-level education and to give HEIs greater autonomy (MOE, 1995). The MOE did implement the final decisions and allowed more and more universities to be established. In both Figures 5 and 6, an expansion curve illustrates the dramatic expansion of HEIs as well as the sharp increase in the rate of university admissions, which reached close to $100 \%$. The sudden change during that period was not incremental at all. According to Baumgartner and Jones (1993), once an idea gains support, it can lead to rapid change and possibly become unstoppable. This is exactly what happened in the first ten years of expansion in Taiwan's higher education from 1996, despite some demographers and sociologists being opposed to setting up more universities (Hsueh, 2003).

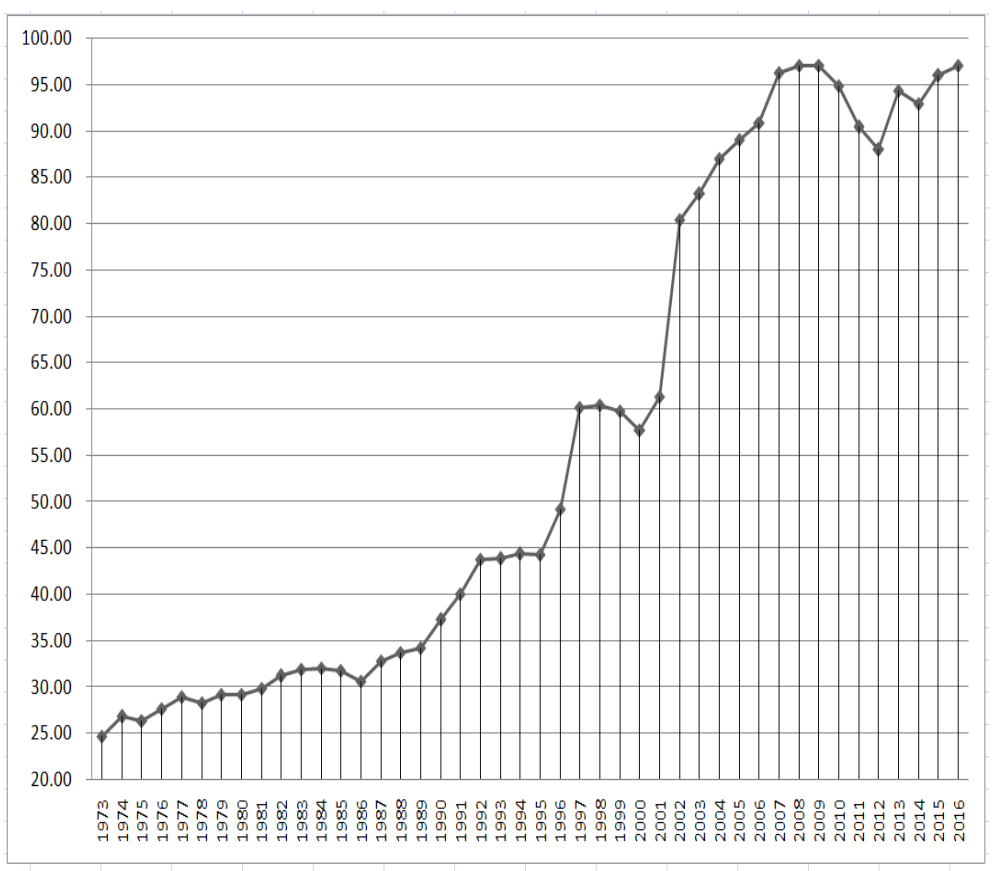

Figure 6. Increasing admission rates for HEIs.

In terms of the declining birthrate, the Ministry of the Interior showed a decrease in the number of births in Taiwan from 271,000 in 1998 to 216,000 in 2003, and 166,000 in 2010 (News, 2015). Currently, there are 158 universities and colleges, 51 public and 107 private, which indicates an oversupply in the market (Kuo, 2016). In 2015, the MOE launched the "Higher Education Innovation and Transformation", which proposed merging between eight and twelve public universities and between 20 and 40 private universities by 2023. In other 
words, the maximum number of HEIs would be 130 and the minimum would be 106 . The Minister of Education, Wu Se-hwa, in a newspaper interview in December 2015, said that Taiwan needed to reduce its number of universities to fewer than 100 within six years or its higher education system would suffer serious consequences due to shrinking enrollment. (CAN news, 2015). With the above policy intervention, reducing the number of HEIs is absolutely essential.

\section{Future Trends in Higher Education in Taiwan from the PET Perspective}

This paper considers three dimensions to estimate the future trends in higher education in Taiwan. The first dimension is the declining birthrate, reducing future enrollment for HEIs, as shown in Figure 4. This is the other trigger for policy change after the overexpansion of HEIs. The second dimension is the public policy "Higher Education Innovation and Transformation" implemented by the MOE. A question that should be asked is why the MOE did not note the declining birthrate in the first place? This sort of oversight happens because of the limits of comprehensive rationality: since decision-makers cannot consider all issues at all times, they sometimes ignore most and promote the relatively few that they are responsible for to the top of their agenda (Baumgartner \& Jones, 1993; 2009; Cairney, 2013; Scribner et al, 2003). To be precise, the policy makers in the 1980s and 1990s in Taiwan were more likely to be considered as bounded nationalists (Simon, 1955). The decision to allow autonomy in higher education is actually bound by the social structures when there are favourable and booming economic conditions.

In order to meet the ideal mechanisms for policy stability, this is a good time for the policy makers (MOE) to solve another conflict: that of declining enrollment and its impact on earlier policy.

The third dimension is to consider how PET can be used to project future trends in higher education. Figure 2 shows the actual and estimated number of freshmen students between 2009 and 2030. The number of HEIs that might be closed or merged in the following ten years could be assessed according to the average number of students who entered the HEIs in the years between 2009 and 2014, divided by the estimated number of students each year. The result of the calculation is shown in Figure 7. The model shown by the dotted line is the possible rapid change followed by further stability. From a long-term point of view, the trend indicates that the number of HEIs in Taiwan may start dropping soon. There are indications that the curve will be going down and that stability could be expected in the education system, according to PET.

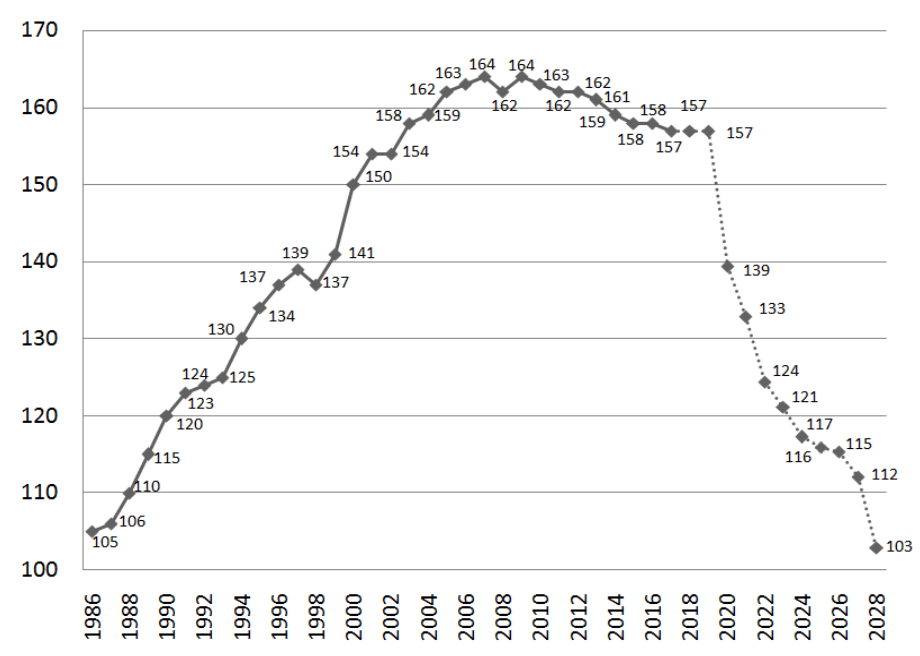

Figure 7. Projecting the numbers of HEIs. 
However, the estimated trend as shown above, would depend on the whole package planned by Taiwan's MOE for those HEIs being adversely affected by low enrollment. The government should be responsible for their transformation or merging HEIs or closing down certain academic faculties.

\section{Conclusion}

Policymaking is affected by many complex components from related areas and policy monopolies. It is also influenced by the public voice and social dissatisfaction or expectation. Taiwan's government facilitated many opportunities for the establishment of new universities or the upgrading of existing colleges during the space of ten years in the 1990s and 2000s This was to meet the social expectations, even though the birthrate had started declining in the 1980s. However, the MOE has released plans for an intervention policy to meet about market balance in higher education. The rapid changes in a short period of time contributed to the sudden increase of number of colleges, which would be followed by a period of equilibrium which aligns with the trends of PET. This paper uses PET to analyze Taiwan's higher education policy changes and reveals the background and conditions of these changes, as well as the ideology of the education reform movement. The paper also provides the expected trends for the future. However, the direction of future trends is based on rational ideas without considering the consequences to universities that may be closed, such as the unemployment of staff and faculties who will lose their jobs. Other issues include the management and operation of the campus buildings, and the arrangements for the current students, etc. must be discussed as a high national priority in an agenda-setting process. Therefore, Taiwan's government needs to consider every aspect before making a policy decision.

\section{References}

Baumgartner, F. (2006). Punctuated equilibrium theory and environmental policy. In R. Repetto (Ed.), Punctuated equilibrium and the dynamics of U.S. Environmental Policy. New Haven: Yale University Press.

Baumgartner, F., \& Jones, B. (1991). Agenda dynamics and policy sub-systems. Journal of Politics, 53(4), 1044-1074.

Baumgartner, F., \& Jones, B. (1993). Agendas and instability in American politics. Chicago: University of Chicago Press.

Baumgartner, F., \& Jones, B. (2009). Agendas and instability in American politics (2nd ed). Chicago: University of Chicago Press.

Cairney, P. (2013). How can policy theory have an impact on policy making? International Conference on Public Policy, Grenoble. June 2013.Retrieved from http://www.icpublicpolicy.org/Expertise-and-involvement-in-the

Cerna, L. (2013). The nature of policy change and implementation: A review of different theoretical approaches. OECD https://www.oecd.org/edu/ceri/The\%20Nature\%20of\%20Policy\%20Change\%20and\%20Implementation.pdf

Chan, S. J., \& Lin, L. W. (2015). Massification of higher education in Taiwan: shifting pressure from admission to employment. Higher Education Policy, 28(1), 17-33.

Chang Chien, C. K., Lin, L. C., \& Chen, C. F. (2013). The main features and the key challenges of the education system in Taiwan. Higher Education Studies, 3(6), 1-14.

Chang, D. F. (2012). College students' perceptions of studying abroad and their readiness. Asia Pacific Education Review, 13(4), 583-591.

Chen, D. S. (2010). Higher education in Taiwan: The crisis of rapid expansion. University in Crisis—Blog of the international Sociological Association (ISA). Retrieved from http://www.isa-sociology.org/universities-in-crisis/?p=417

Chin. M. C., Kuo, S. Y., \& Wu, W. D. (2002). Review of high school and university admission system. Toward a Normal Nation: A Proceedings of the Symposium on National Politics (284-303). Taipei: Institute for Information Industry (In Chinese).

Chou, C. P. (2014). Syndrome in Taiwan's academia. Education Policy Analysis Archives, 22(29), 1-22.

Chou, C. P. (2015). Who benefits from Taiwan's mass higher education? In C. S. Jung and G. Postiglione, Mass Higher Education Development in East Asia. Strategy, Quality, and Challenges. Volume 2 of the Series Knowledge Studies in Higher Education, 231-243. 
Giroux, H. A. (2002). Neo-liberalism, corporate culture, and the promise of higher education: the university as a democratic public sphere. Harvard Educational Review, 72(4), 1-31.

Givel, M. (2010). Unexplained and anomalous policy output patterns in punctuated equilibrium theory: Challenging the dominant paradigm and building a better theory. Presented to: Challenging Orthodoxies: The Critical Governance Studies Conference 13-14, December 2010, University of Warwick, U.K.

Gould, S., \& Eldredge, N. (1977). Punctuated equilibrium: The tempo and mode of evolution reconsidered. Paleobiology, 3 , 115-151.

Ho, C. H. (2012). The evaluation of career preparation behavior model for the collegiate athletes with confirmatory factor analysis. Journal of Sport and Recreation Management, 9(2), 192-201.

Hou, A. Y. C. (2012). Development of Taiwan's research excellence initiative and its impact on Taiwan higher education. Journal of International Higher Education, 5(2), 70-73.

Hsueh, J. (2003). Ten-year educational reform built a dream for whom?_From sociology and demography views. Taipei: Psychology Publishing Company (In Chinese).

Hsueh, J. (2009). The impact of declining births on the development of senior high schools: A sociological perspective. China Education, 60(1), 8-19.

Hsung, R. M., F. B. Chang, \& Y. F. Lin. (2010). Changes in participation in Post-Martial Law Voluntary Associations: Effects and implications of period and cohort. Taiwanese Journal of Sociology, 44, 55-105 (in Chinese).

Hwang, K. K. (2003). What are mistakes in educational reform?-My scheme. Taipei: INK Publishing Company (In Chinese).

Hwang, K. K. (2016). Academic self-colonization and the crisis of higher education in Taiwan and mainland China. Chinese education models in a global age (pp. 77-86). Berlin/Heidelberg, Germany: Springer Science + Business Media Singapore 2016.

Jones, B. D., \& Baumgartner, F. R. (2012). From there to here: Punctuated equilibrium to the general punctuation thesis to a theory of government information processing. Policy Studies Journal, 40(1), 1-19.

Kuo, Y. Y. (2016). Taiwan Universities: Where to go? Humanities, 2016, 5, 12. doi:10.3390/h5010012.

Law, W. W. (2002). Education reform in Taiwan: A search for a "national” identity through democratization and Taiwanisation. Compare, 32(1), 61-81.

Lin, Y. F. (2014). Clarifications of diploma inflation. Taiwan Educational Review, 3(12). 1-3. (In Chinese).

May, X. R., Chang, F. B., \& Lin, Y. F. (2010) The trend of public association participation after the lift of martial law: the effects and meanings of periods and era. The Taiwanese Journal of Sociology, 44, 55-105. (In Chinese).

Ministry of Education. (1994a). Education in the Republic of China. Taipei, Taiwan: Bureau of Statistics, Ministry of Education.

Ministry of Education. (1994b). The Minutes of National Education Conference. Taipei, Taiwan: Ministry of Education.

Ministry of Education. (1995). Education Report of the Republic of China. Taipei, Taiwan: Ministry of Education.

Ministry of Education. (2012a). Summary of statistics: Summary of education at all levels in SY 2011. Retrieved from http://english.moe.gov.tw/ct.asp?xItem=12862\&ctNode=1184 \&mp=1

Ministry of Education. (2012b). Higher education in Taiwan 2012-2013. Retrieved from http://www.edu.tw

Ministry of Education. (2013a). Educational statistics. Retrieved from http://www.edu.tw/Default.aspx?WID=31d75a44-efff-4c44-a075-15a9eb7aecdf

Ministry of Education. (2013b). White paper on national cultivation of talents. Retrieved from http://ws.moe.edu.tw/001/Upload/3/RelFile/6315/6919/教育部人才培育白皮書.pdf

Ministry of Education. (2015a). Survey on number of enrolled students and schools at each education level (written in Chinese). Retrieved from http://www.edu.tw/pages/detail.aspx?Node=4075\&Page=20046\&Index=5\&WID=31d75a44-efff-4c44-a075-15a9eb7aecdf

Ministry of Education. (2015b). Higher education innovation and transformation. Retrieved from https://heitoplus.edu.tw/upload/download1fs1160401580342156.pdf

Ministry of Education. (2016a). Predicting the enrollment of higher education. Retrieved from http://www.edu.tw/News_Plan_Content.aspx?n=D33B55D537402BAA\&sms=954974C68391B710\&s=889A5EA64C666473

Ministry of Education. (2016b). Summary of tertiary education institutes (2015-2016). Retrieved from http://stats.moe.gov.tw/files/main_statistics/u.xls

Ministry of Education. (2016c). 2017 directions of policy implementing. Retrieved from http://depart.moe.edu.tw/ED2100/News_Content.aspx?n=D23E9B1FC9ED5D63\&sms=4186928212B88A3A\&s=424DCB9 2C1DDC710 
News (2015). Retrieved from http://focustaiwan.tw/news/afav/201512120024.aspx

News (2016a). Retrieved from http://a.udn.com/focus/2016/08/08/23749/index.html?from=udn-referralnews_ch1012artbottom

News (2016b). Retrieved from http://www.ettoday.net/news/20160327/670275.htm (03272016)

Pan, H. L. (2011). Review of the Chinese education in past 100 years-Inheritance and Innovation. Review of the educational reform in past 10 decades. Taipei: Pro-ed publishing company. (In Chinese).

Schofer, E., \& Hironaka, A. (2005). World society and environmental protection outcomes. Social Forces, (84), 25-47.

Scribner, J., Aleman, E., \& Maxcy, B. (2003). Emergence of the politics of education field: Making sense of the messy center. Educational Administration Quarterly, 39(1), 10-40.

Simon, H. A. (1955). A Behavioral model of rational choice. The Quarterly Journal of Economics, 69(1), 99-118.

Simon, H. A. (1955). A behavioral model of rational choice. The Quarterly Journal of Economics, 69(1), 99-118.

Tang, C. -M. (2003). The analysis of Taiwan's higher education merger and expansion. Retrieved from: www3.nccu.edu.tw/ tangcm/doc/2.html/article/E219.pdf (05082017)

Trow, M. A. (2006). Reflections on the transition from elite to mass to universal Access: Forms and phases of higher education in modern societies since WWII. In International Handbook of Higher Education (18), 243-280. P. G. Altbach (Ed.). New York: Springer.

True, J. L., Jones, B. D., \& Baumgartner, F. R. (1999). Punctuated-equilibrium theory: Explaining stability and Ahange in American policymaking. In P. A. Sabatier (Ed.), Theories of the policy process (pp. 97-115). Boulder: Westview Press.

True, J. L., Jones, B. D., \& Baumgartner, F. R. (2007). Punctuated equilibrium theory' in (ed.) p. sabatier theories of the policy process (2nd edition). Cambridge MA: Westview Press.

Tsai, S. L., \& Shavit, Y. (2003). Higher education in Taiwan: Expansion and inequality of educational opportunity. Paper presented at the International Sociology Association RC28 Research Committee on Social Stratification and Mobility's New York Meeting, August 22-24.

Tu, C. -S. (2007). Taiwan's educational reform and the future of Taiwan. Invited speech presented at London School of Economics and Political Science. Retrieved from http://www.lse.ac.uk/collections/taiwanProgramme/TaiwanEducationalReform_English.pdf

Yang, S. -W. (2001). The development of mass higher education. Educational Research \& Information, 8(4), 17-31. 